\title{
The Space Construction of Gothic Architecture in Narration in the Notre Dame of Paris
}

\author{
Qin Bin \\ College of Foreign Languages, Neijiang Normal University, Sichuan 641112, China.
}

Keywords: Gothic architecture; narrative; space construction; Notre Dame de Paris.

\begin{abstract}
This paper takes the Gothic architecture in the Notre Dame de Paris as the object of study, and studies the role of spatial narration in the narrative of the novel. Mainly from the following aspects to explore: First, the "Notre Dame" description of the characteristics of Gothic architecture and Gothic architecture in the "geometry" in the meaning. Second, elaborate the "Notre Dame de Paris" this work, with its literary value and profound social significance of the study of the necessity of this novel. Third, discuss the spatial function of Gothic architecture in narrative.
\end{abstract}

\section{Introduction}

Architecture has often become a literary creation of the scene, and, through the ages also presents a lot of classic literary works. In the history of Chinese and foreign literature, there have been many literary works, China's "Dream of Red Mansions", "West Chamber", Japan's "Golden Pavilion Temple", the British "Sherlock Holmes Detective Case", France's "human comedy" Set the scene, launched the life of the painting to write an important literary works, and spread through the ages.

However, Victor Hugo is a famous French writer, "Notre Dame de Paris" is one of his classic works, in the Notre Dame de Paris, a large number of Gothic architecture description, making this work more meaningful The This article mainly from the characteristics of Gothic architecture and Gothic architecture in the "geometry" in the meaning of the Gothic architecture in the "Notre Dame de Paris" in the narrative and theme, characters and plot integration. Hugo is a literary writer, there are a lot of masterpieces, but "Notre Dame de Paris" is the closest combination of literature and architecture in many works, from the architectural point of view to explore the role of narrative space, give us really left a lot of questions worth exploring.

\section{About Gothic architecture}

Gothic architecture can also be translated as Goethe-style architecture, a prosperous in the medieval peak and the late architectural style. Gothic architecture at that time was a lot of people called "French", after the Renaissance appeared "Gothic" word, and with derogatory.

Towering minarets, pointed arches, huge windows, and painted windows with large biblical stories are characteristic of Gothic architecture. Gothic architecture in the design of the use of vault, flying buttress and beam column to create a light atmosphere, giving a sense of flying, the church is designed for the Latin cross, a pair of towers placed on both sides of the western end of the door, the sharp ribs of the thrust will act on the four huge arch stone, so that the vault from the height and span restrictions, The formation of large and high space. Gothic architecture is characterized by: (1) the arch of the doors and windows, making the doors and windows have a very sense of the sense of direction (2) with long beam column technology, the vertical sense of strong (3) (4) ethereal flying buttress (5) multi-faceted varnish pattern, with rose style and flame pattern, are religious and aesthetics (4) The combination of many windows also have colored glass, so that the indoor luster has a fantastic color, giving a sense of mystery. [1]

Architecture and narration will be with the time, shining. Gothic architecture contains knowledge of the seven disciplines of the middle Ages, the most significant of which is geometry. Because the architects at that time the use of geometric combination of the way to create the Gothic architecture, making the geometry of Gothic architecture is another major feature. 
Hugo in the "Notre Dame de Paris" narrative grasp the combination of geometric surface of this feature and the formation of the spatial narrative geometric style, that is, all the description of the object are building, geometric, in this work, he put the Abstract objects and specific objects are represented by geometric shapes. The description of geometric shapes is everywhere in the novel, such as "triangular", "square", "parallelogram", "pentagon", "hexagon", "polygon", "unequal square", "parallel Hexahedron "," cube "and so on. Hugo depicts the human body, face, environment, spirit and the universe are the architectural geometry applied to the performance of the text narrative, this conscious use in the narrative of this work can be seen everywhere. Hugo is a very romantic scientist who emphasizes the spirit of science, and he particularly responds to mathematics. He said: "There are three keys in the human spirit: the number of words, words and notes, human understanding, thinking, dreams, all here." ${ }^{1} \mathrm{He}$ always combines literary imagination with mathematics and geometry, which has become his important aesthetic thought. In the Shakespeare theory, he devoted himself to the relationship between nature and art, that "In principle, the law of art is the law of nature. The angle of reflection is equal to the angle of projection." ${ }^{2}$ Poetry is like science, there is an abstract source, Science produces material, poetry produces spiritual masterpiece. The number is the foundation of human thought. "There is no number, there is no science; no number, no poetry, and all abstract and imaginary things are subject to the "number" of the mysterious words of domination, as geometry and mathematics", when the scientific development to the final stage, then combined with the imagination. "In the algebra used in geometry, imagination is the coefficient of calculation, so mathematics has become a poem." "Notre Dame de Paris" is the author of geometry and imagination combined with the practice of crystallization, Hugo's imagination always And the description of the geometric graphics is not cut off, so when writing to the Gothic architecture he always can open the imagination of the wings to create, the geometric construction of space implicit in the author's aesthetic thinking, This is the harmony of his novels in the geometric graphics of things after the description: "They participate in all without confusion, they make it full and not overload. Geometry is a harmonious knowledge.

\section{Notre Dame de Paris}

"Notre Dame de Paris" was written by Victor Hugo in 1830 under the influence of the French "July Revolution" and the feudal restoration dynasty was overthrown. When he was very young on the Gothic architecture art had a strong interest in the change over time, age is growing, the love of Gothic architecture is also growing, has repeatedly entered the Notre Dame to access the Senate The Gothic architecture of the information, and boldly put forward a hypothesis: once in such a towering bell tower in the dark corner of the wall, found the medieval characters handwritten Greek words: fate! The fate of the word deeply beat the author's heart, not only the meaning of the surface of the word, or the meaning of its place. At that time, in the excitement of Hugo did not hesitate to put Notre Dame as a creative background, launched a bold imagination and re-creation, for everyone to create a good pure Gypsy girl, looks very ugly but inner Full of righteousness of the sound of the bell, a serious but full of lust of Frederick and other classic characters. Hugo's literature, caused by a sensational romantic novel was born, "Notre Dame de Paris" come out, whether in literature or in the impact on society, have a very lucrative significance. Even today, two centuries later, "Notre Dame de Paris" is still being reprinted over and over again. In the process of reading this book can feel that the details of the Gothic architecture description, the book of characters and events, in the writer's heavy color under the composition of a magnificent and strange picture, the novel to make People are fascinated by the wonderful flowers, detailed observation, opened the mystery of the Gothic architecture, described the Gypsy girl Esmeralda, knocking bells Casimodo, a serious bishop and several other major characters fate Of the dispute, conflict, destruction.

\section{The Construction of Gothic Architecture in the Narrative of Novels}

In this novel, the narrative function of space is mainly manifested in: space on the arrangement of the plot of the novel, the control of the rhythm and the appearance of the characters will have an 
impact. In the "Notre Dame de Paris", the preface, the second volume, the fifth volume are basically in the large length of the description of the Gothic architecture, accounting for one third of the novel. It is clear that the description of the Gothic architecture is a major object of the description and discussion of the novel. Many writers have discussed that the success of this novel is a large part of the reason, thanks to the Gothic architecture meticulous clever characterization. The unique description of the Gothic architecture, occupies a very unique position, the promotion of the theme, the shape of the characters and the promotion of the plot are reflected in the narrative text in the role and significance. In the "Notre Dame de Paris", the description of the Gothic architecture changes the performance of the traditional narrative in the text, the geography of the narrative, the art space of the narrative of the novel. The author describes the object is not only the Notre Dame Church This Gothic building, which will be the whole city of Paris, Gothic architecture are included in the pen, making the Gothic architecture in the novel narrative everywhere, always exist. The Notre Dame Church in Paris itself is a typical Gothic building, an epoch-making sign in the history of European architecture. "Notre Dame de Paris" was created by the influence of the "July Revolution". When the world is reading this work, the words between the anti-feudal ideas, anti-feudal struggle, calling for the beauty of human nature, advocating the idea of freedom of the people will be deeply encouraged by them.

The concept of the characters in the theory of literature is "the inner power of the human being as a story and the development of the plot and the center of the text." In the "Notre Dame de Paris", the relationship between architecture and character is very close, this novel building is a life, architecture is not only a novel scene, it is the character of the environment, and for the character of the human Display aspects have a very important significance.

In the "Notre Dame de Paris", all the narratives from the description of the Gothic architecture began, all the narrative are closely linked with the Gothic architecture, the novel a total of 11 volumes, starting from the description of the work, followed by the Gothic The buildings are: French Hall, Gothic Square, Notre Dame Church, Gothic House, Gothic Prison, Notre Dame. From this arrangement, we clearly see that in this work, all the Gothic buildings in the city of Paris are included in the pen, the building and the narrative cannot be separated. The activities of the characters are inseparable from the Gothic architecture, and the Gothic architecture becomes the main space of the narrative of the novel, providing an environment for the story and the characters of the novel. For example, the "fool king election" mentioned in the first volume is held at Notre Dame Square. Later, "Esmeralda was sent to hide in the Notre Dame de Paris" set off the climax of the novel, so the Gothic architecture in this work is the main activities of the people of the environment.

The projection effect of Gothic architecture is also reflected in the projection space supported by the Notre Dame de Paris, breaking the characteristics of the traditional Western-style novels. The author has established a circular structure in the narrative of time. The combination of the "point" and "face" of the projection is also a combination of the historical and imaginary spatial nature of the narrative. "Notre Dame de Paris" This work, under the influence of the Gothic architecture, the character movement formed a circular frame, that is, all the characters in the works are gathered from all directions to a focus, Meharda body, the beautiful gypsy girl's encounter, the deputy bishop Claude $\mathrm{Fu}$ Ronuo with their own strong desire to love the mouth of the United States marked the "fate" of the unbreakable knot card The appearance of the ugly deformity of Simo, always transcends the line that cannot cross between him and Esmeralda; these form a circular structure of the characters who are centered on Esmehardda. We believe that the circular structure of the characters with the heart of Esmehardda is derived from the influence of the space structure of Notre Dame as the center, and the author describes the character structure as the center in the Gothic building of the Notre Dame de Paris, and to the surroundings of the cast.

\section{Conclusion}

"Notre Dame de Paris" in the architectural description not only has a high aesthetic value, but also a complete embodiment of Hugo's humanitarianism. Indeed, Hugo as a great writer, in his description of the Gothic architecture, whether in the theme of the publicity, or in the plot to promote, or in the shape of the characters is very representative. His literary thought from the early romanticism to the 
later critical realism, making his architectural aesthetic has also changed. "Notre Dame de Paris" in the description of the Gothic architecture is his love for the concrete performance of the building. From his nostalgic description of the Gothic architecture and the Gothic architecture projected by the Notre Dame to the whole of Paris, it not only allows us to understand the architectural facade of the French church at that time, but also let us from a new perspective to observe the works, that is, from the perspective of space construction to explore the text narrative, appreciate the character of a series of activities. Therefore, from the perspective of space construction in the narrative art of architecture, it makes the literary meaning of Notre Dame de Paris more accurate.

\section{References}

[1] Xiaomin Li. Study on decorative art of painted glass windows in Gothic architecture [D]. Anhui: Anhui Finance and Economics University, 2015.

[2] Dan Fu. Literary Narrative and Architectural Art of Notre Dame in Paris[D]. Hubei: Huazhong Normal University, 2004.

[3] Mei Zhao. The "fate" carved in the belfry. [J]. world culture, 2015, (7): 43-45.

[4] Fengying Zhang. Analysis of the relationship between the characters in Notre Dame de Paris and Notre Dame[J]. Journal of Chifeng University (Chinese philosophy and Social Science Edition), 2016, (6): 194-196.

[5] Wei Li. "Notre Dame de Paris": Architecture in the View of Literature [D]. Hunan: Central South University, 2008.

[6] Old sea. Notre Dame de Paris: huge stone buildings [J]. Shanghai real estate history, 2014, (12): 53.

[7] Na Peng. Gothic architecture of the aesthetic significance [D]. Chengdu: Sichuan Normal University, 2012.

[8] Jin $\mathrm{Xu}$. On the Gothic Architecture Art in Europe and Its Influence[D]. Shandong: Shandong University, 2010.

[9] Rui Shi. From "a dream of Red Mansions" "Notre Dame de Paris" in the comparison of Chinese and Western architectural culture [J]. Architecture, 2010, (19): 76-77. [10], Kuang Wenqiang, Chen Hongguang. Stone room "Gothic" architectural style [J]. Foreign construction, 1995, (1): 31. 